\title{
An Unusual Case of Neuralgic Amyotrophy Presenting with Bilateral Phrenic Nerve and Vocal Cord Paresis
}

\author{
F. Holtbernd ${ }^{a} \quad$ A. am Zehnhoff-Dinnesen ${ }^{b} \quad$ T. Duning ${ }^{a}$ \\ A. Kemmling ${ }^{c} \quad$ E.B. Ringelstein ${ }^{a}$ \\ Departments of a Neurology, bPhoniatrics and Pedaudiology and 'Radiology, \\ University Hospital of Muenster, Muenster, Germany
}

\section{Key Words}

Neuralgic amyotrophy · Neuropathy · Parsonage-Turner syndrome - Laryngeal palsy . Diaphragmatic palsy

\begin{abstract}
Background: Neuralgic amyotrophy (brachial plexus neuropathy, brachial plexus neuritis, or Parsonage-Turner syndrome) is an uncommon inflammatory condition typically characterized by acute and severe shoulder pain followed by paresis with muscle weakness and atrophy of the upper limb or shoulder girdle. We report an unusual clinical manifestation of neuralgic amyotrophy, namely bilateral phrenic nerve palsy with concomitant laryngeal paresis.
\end{abstract}

Case Report: A 55-year-old male presented with orthopnea and aphonia after an episode of bilateral shoulder pain preceded by an upper respiratory tract infection. Spirometry, chest X-ray and videolaryngoscopy revealed bilateral and simultaneous paresis of the diaphragm and the vocal cords. Clinical examination at admission and at the 2-month follow-up did not show upper limb weakness or atrophy, except for a mild atrophy of the right supraspinatus muscle. An electromyography of the upper limb muscles and nerve conduction studies did not reveal signs of denervation. Analysis of the cerebrospinal fluid and an MRI of the neuraxis were unremarkable. After treatment with prednisolone, vocal cord function markedly improved within 8 weeks, whereas paresis of the diaphragm persisted.

Conclusion: Shoulder pain followed by diaphragmatic paralysis with dyspnea and hoarseness may be a manifestation of neuralgic amyotrophy even if upper limb or shoulder girdle palsies are absent. 


\begin{tabular}{c|l|l|l} 
Case Reports in & Case Rep Neurol 2011;3:69-74 & $\begin{array}{l}\text { Published online: } \\
\text { February 23, 2011 }\end{array}$ & $\begin{array}{l}\text { ○ 2011 S. Karger AG, Basel } \\
\text { ISSN 1662-680X } \\
\text { www.karger.com/crn }\end{array}$ \\
\hline
\end{tabular}

\section{Introduction}

Neuralgic amyotrophy (NA) is an uncommon neuropathy first described in 1948 by Parsonage and Turner [1]. Typically, the earliest manifestation of this disease is a sudden onset of severe and sharp pain in the shoulder lasting for 2-4 weeks, mostly followed by a sudden weakness and gradual atrophy of the muscles innervated by the C5-6 or other nerve roots in the vicinity. Rare manifestations include isolated or concomitant affection of other peripheral motor nerves derived from the cervicobrachial plexus, such as the phrenic or laryngeal nerves [2-5]. Very rarely, bilateral pareses of the diaphragm or laryngeal palsies had been observed [6-8].

The incidence of NA is estimated at 2-4/100,000 per year [1]. Although the pathogenesis of NA is unknown, an idiopathic autoimmune process triggered by an unspecific infection is presumed. Infections of the respiratory tract, trauma or surgery of the shoulder often precede the onset of NA. Besides the idiopathic form, a hereditary autosomal dominant form caused by a mutation in the SEPT9 gene on chromosome $17 q 25$ has recently been described [9]. In the majority of patients, the course of NA is benign, with recovery of muscle function within weeks to months. However, $25 \%$ of the patients are not able to return to work after 3 years [1].

The diagnosis of NA relies on a characteristic history of severe pain in the shoulder, followed by pain relief and subsequent brachial palsies. Chest X-ray and cerebrospinal fluid analysis should be obtained to rule out a direct viral or bacterial infection, or a mechanical compression of the brachial plexus. Electrophysiological examination may show axonal injury, demyelination and spontaneous muscle activity. Plexus MRI usually reveals no pathological findings, although $\mathrm{T} 2$ hyperintensities may occasionally be observed [10]. Corticosteroids seem to accelerate the recovery of NA patients and are recommended in the early stages of the disease [11]; however, there are no randomized controlled treatment studies of NA conducted to date.

We report an unusual case of NA presenting with simultaneous, bilateral phrenic nerve palsies and vocal cord paresis as the predominant symptoms, with partial gradual recovery after 2 months. Written informed consent was obtained from the patient for publication of this case report and any accompanying images.

\section{Case Report}

A 55-year-old male patient with an unrevealing medical history except for nicotine abuse (50 pack years) presented with an acute onset of dyspnea and aphonia. About 7 weeks before referral to our tertiary neurological center, the patient had suffered a viral infection of the upper airways, which was followed by a distinct sharp pain in both shoulders lasting for several days. The pain subsided; however, the patient developed increasing shortness of breath and orthopnea. Cardiac insufficiency was ruled out and an echocardiography was unremarkable. A chest CT was normal and spirometry showed a reduced vital capacity and a reduced forced expiratory vital capacity per second. The working diagnosis of chronic obstructive lung disease was made, and the patient was discharged on inhaled fenoterol and ipratropium bromide.

Five days later, the patient suffered from progressive hoarseness, leading to complete aphonia within $48 \mathrm{~h}$. He complained of the impossibility to cough and to clear his throat. The initial neurologic examination at our department showed no weakness or atrophy of the upper limbs and normal tendon reflexes. Sensibility and cranial nerve functions were normal. The patient was short of breath with 
paradoxical abdominal movement, extensive use of the accessory respiratory muscles and a slight inspiratory stridor which prevented him to sustain a supine position.

A chest CT and a whole-body positron emission tomography-CT showed no evidence of malignancy or inflammation. An X-ray cinematography of the chest revealed an elevated diaphragm with only marginal movement during inspiration (fig. 1). Videolaryngoscopic examination showed signs of partial paralysis of both branches of the vagus nerves, namely both the recurrent laryngeal nerves and the superior laryngeal nerves. The excavated vocal folds were in an intermediate position, with minimal non-intended adduction movements. The muscle tension of the ventricular folds was decreased (fig. 2).

A needle electromyography (EMG) of the right and left $\mathrm{m}$. biceps brachii, the right $\mathrm{m}$. infraspinatus and $\mathrm{m}$. extensor pollicis longus and the left $\mathrm{m}$. deltoideus, $\mathrm{m}$. trapezius and paravertebral muscles was normal, without pathological spontaneous activity. Motor and sensory nerve conduction velocities including phrenic nerve conduction were normal, as were the F-waves. Fiberoptic endoscopic examination of swallowing was unrevealing. Polygraphy showed a regular nocturnal oxygen saturation without hypercapnia. Spirometry revealed a reduction of the forced expiratory vital capacity per second ( $66 \%$ of reference) and of the vital capacity ( $75 \%$ of reference). The maximum inspiratory pressure was severely reduced (34.3\% of reference), whereas the maximum expiratory pressure was not decreased (table 1). Blood gases were within the normal range. Because of severe dyspnea when lying down, lung function testing could not be performed in the supine position. Cell count and protein concentration of the cerebrospinal fluid were normal. Magnetic resonance imaging of the myelon and brain did not show any abnormalities. The diagnosis of bilateral NA was made, and the patient was treated with intravenous corticosteroids (500 mg methylprednisolone for 5 days).

At reassessment after 2 months, phonation had markedly improved, but hoarseness was still present. Further neurological examination remained unchanged, except for a mild atrophy of the right supraspinatus muscle. During videolaryngoscopy, the excavated vocal cords were mobile; however, during phonation, glottal closure was still insufficient over the whole length of the glottis. While the gap between the processus vocales was closely to $1 \mathrm{~mm}$, it was approximately $2 \mathrm{~mm}$ between the excavated vocal folds in the mid of the glottis (fig. 2). Tension of the ventricular folds returned to normal. Results of the EMG, phrenic nerve conduction velocity, lumbar puncture and spirometry were unaltered. A chest X-ray revealed an unchanged elevation of the diaphragm, with restricted mobility during inspiration.

\section{Discussion}

The typical course of NA is initiated by a distinct pain in the shoulder, followed by muscle weakness and atrophy. However, NA involving other peripheral nerves or isolated affection of single motor nerves can be difficult to diagnose. In our case, acute-onset dyspnea and orthopnea were the predominant symptoms suggestive of a cardiac etiology or bronchial asthma. The rapidly progressive hoarseness, leading to aphonia within $48 \mathrm{~h}$ and worsening of dyspnea when lying flat, was indicative for an atypical NA [3, 7, 12]. A decrease in the forced vital capacity of more than $40 \%$ in the standing compared to the supine position is suspicious of diaphragmatic paresis; therefore, the forced vital capacity should be assessed in both positions, if possible. Phrenic nerve conduction velocity can be prolonged or, as in our case, normal [5]. The EMG of the diaphragm could have helped to confirm the diagnosis of diaphragmatic paralysis $[3,13]$, but was not performed in our case due to the associated relatively high risk of pneumothorax. The chest X-ray revealed an elevated diaphragm on both sides with nearly no movement during inspiration, and the maximum inspiratory pressure was severely reduced.

Laryngeal paresis is a rare feature of NA $[2,6]$. To and Traquina [14] reported a case of a child with bilateral vocal cord paresis due to NA. Our patient suffered from partial paralysis of both recurrent laryngeal nerves. Since both superior laryngeal nerves were additionally affected, glottic stenosis was incomplete and the patient was still able to 
breathe spontaneously, although a slight inspiratory stridor was noticed on auscultation. Recovery of respiratory muscle weakness can take months to years, and only about $50 \%$ of the patients experience an improvement of respiratory function [12], whereas improvement of laryngeal paresis usually occurs faster $[2,14]$. In our case, phonation markedly improved within 8 weeks.

The diagnosis of NA in this case was based on the affection of multiple motor nerves, the typical onset of the disease, the reported shoulder pain and the negative results of additional diagnostics. Isolated phrenic nerve paralysis without weakness of the upper limbs despite normal EMG and nerve conduction velocities has been described to occur in NA $[3,5,8,12]$. However, to the best of our knowledge, bilateral and simultaneous vocal cord paresis with concomitant bilateral palsy of the diaphragm without involvement of the proximal upper limb muscles or weakness of the shoulder girdle has not been reported in NA so far.

\section{Conclusion}

Orthopnea and laryngeal paresis may be the only manifestations of NA. Therefore, physicians should be alerted to a preceding history of an upper airway infection and shoulder pain even if pareses of the upper limbs and the shoulder girdle are absent and the EMG and nerve velocity conduction studies are unrevealing.

\section{Acknowledgement}

We would like to thank Dr. med. Sabine Kessler, Head of the Department of Phoniatrics, Klinik am Osterbach, Bad Oeyenhausen, Germany, for the right to use the photography taken during videolaryngoscopy directly after the initial visit.

\section{Disclosure Statement}

E.B. Ringelstein has received travel expenses and honorariums from Boehringer Ingelheim, Sygnis, Neurobiological Technologies, Novartis, Novo-Nordisc, Sanofi-Aventis, Solvay, Bayer Vital, M's Science, Sevier, UCB, and Trommsdorff for serving as a member of Steering Committees, Safety Committees in clinical trials, and as a speaker and consultant. He has no ownership interest and does not own stocks of any pharmaceutical company. All other authors have no financial or nonfinancial competing interests to report. 


\begin{tabular}{l|l|l|l} 
Case Reports in & $\begin{array}{l}\text { Case Rep Neurol 2011;3:69-74 } \\
\text { DOl: 10.1159/000325061 }\end{array}$ & $\begin{array}{l}\text { Published online: } \\
\text { February 23, 2011 }\end{array}$ & $\begin{array}{l}\odot \text { ISSN 1662-680X } \\
\text { www.karger.com/crn }\end{array}$ \\
\hline
\end{tabular}

Table 1. Results of spirometry showing mild airflow obstruction and severe inspiratory restriction

\begin{tabular}{lrc}
\hline Spirometry & Result & \% of reference \\
\hline VC, liter & 3.62 & 75.1 \\
FVC, liter & 3.39 & 73.2 \\
FEV $_{1}$, liter & 2.43 & 65.9 \\
$\mathrm{RV}_{\text {, liter }}$ & 3.03 & 130.7 \\
$\mathrm{PI}_{\max }$, mbar & 3.57 & 34.3 \\
$\mathrm{PE}_{\max }$, mbar & 12.81 & 94.8 \\
\hline
\end{tabular}

$\mathrm{VC}=$ Vital capacity; FVC = forced vital capacity; $\mathrm{FEV}_{1}=$ forced expiratory volume per 1 second; $\mathrm{RV}=$ residual volume; $\mathrm{PI}_{\max }=$ maximal inspiratory pressure; $\mathrm{PE}_{\max }=$ maximal expiratory pressure.

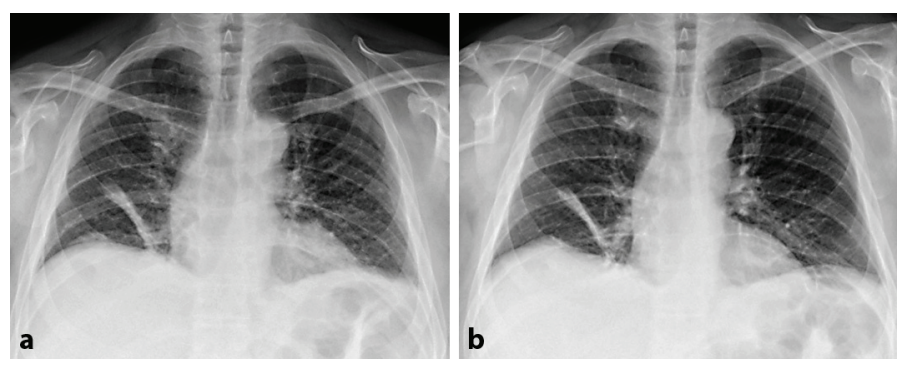

Fig. 1. Chest $\mathrm{X}$-ray at initial visit in maximum expiration (a) and maximum inspiration (b), showing paresis of the diaphragm and partial atelectasis of the right lung.
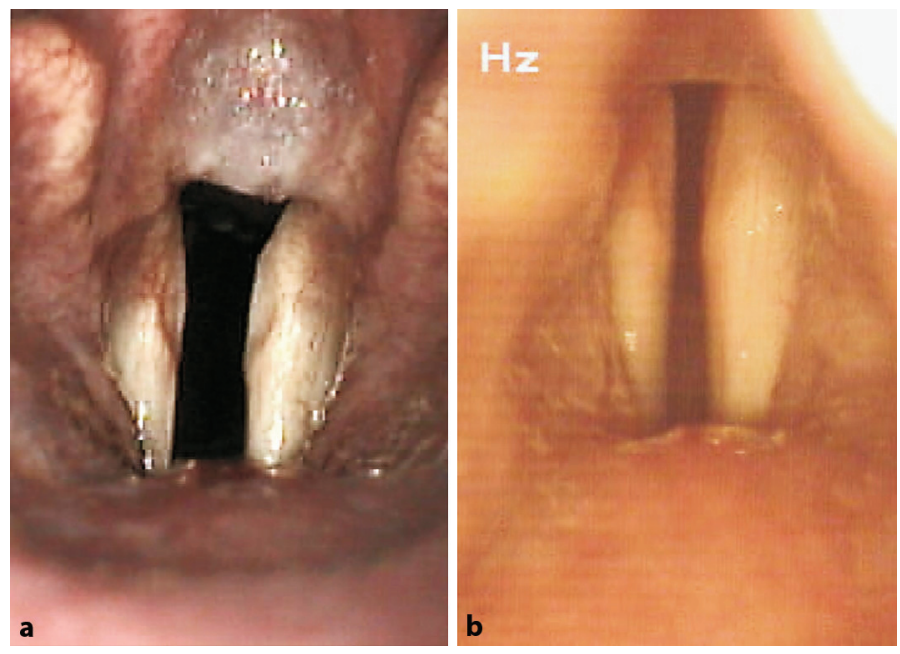

Fig. 2. Videolaryngoscopy during phonation after the initial visit (a) and at the 2-month follow-up (b), demonstrating an improvement of the vocal cord mobility and a normalization of the ventricular fold tension. 


\begin{tabular}{c|l|l|l} 
Case Reports in & Case Rep Neurol 2011;3:69-74 & $\begin{array}{l}\text { Published online: } \\
\text { February 23, 2011 }\end{array}$ & $\begin{array}{l}\text { ○ 2011 S. Karger AG, Basel } \\
\text { ISSN 1662-680X } \\
\text { www.karger.com/crn }\end{array}$ \\
\hline
\end{tabular}

\section{References}

1 Parsonage MJ, Turner JW: Neuralgic amyotrophy: the shoulder-girdle syndrome. Lancet 1948;1:973-978.

- Hyde GP, Postma GN, Caress JB: Laryngeal paresis as a presenting feature of idiopathic brachial plexopathy. Otolaryngol Head Neck Surg 2001;124:575-576.

3 Lahrmann H, Grisold W, Authier FJ, Zifko UA: Neuralgic amyotrophy with phrenic nerve involvement. Muscle Nerve 1999;22:437-442.

4 Tsairis P, Dyck PJ, Mulder DW: Natural history of brachial plexus neuropathy. Report on 99 patients. Arch Neurol 1972;27:109-117.

5 Tsao BE, Ostrovskiy DA, Wilbourn AJ, Shields RW Jr: Phrenic neuropathy due to neuralgic amyotrophy. Neurology 2006;66:1582-1584.

6 Chen YM, Hu GC, Cheng SJ: Bilateral neuralgic amyotrophy presenting with left vocal cord and phrenic nerve paralysis. J Formos Med Assoc 2007;106:680-684.

7 Kalluri M, Huggins JT, Strange C: A 56-year-old woman with arm pain, dyspnea, and an elevated diaphragm. Chest 2008;133:296-299.

- Ikegami G, Abe T, Akasaka K, Kouyama A, Souma R, Matsuo T, Kouyama K, Fujiwara H, Ichiwata T, Nagao $\mathrm{K}$ : Bilateral phrenic nerve paralysis manifested by orthopnea for 6 months in a patient with neuralgic amyotrophy. Intern Med 2009;48:2123-2127.

-9 Kuhlenbäumer G, Hannibal MC, Nelis E, et al: Mutations in SEPT9 cause hereditary neuralgic amyotrophy. Nat Genet 2005;37:1044-1046.

10 Gaskin CM, Helms CA: Parsonage-Turner syndrome: MR imaging findings and clinical information of 27 patients. Radiology 2006;240:501-507.

11 van Alfen N, van Engelen BG, Hughes RA: Treatment for idiopathic and hereditary neuralgic amyotrophy (brachial neuritis). Cochrane Database Syst Rev 2009:CD006976.

$\checkmark 12$ Kumar N, Folger WN, Bolton CF: Dyspnea as the predominant manifestation of bilateral phrenic neuropathy. Mayo Clin Proc 2004;79:1563-1565.

13 Nardone R, Bernhart H, Pozzera A, Taddei M, Tezzon F: Respiratory weakness in neuralgic amyotrophy: report of two cases with phrenic nerve involvement. Neurol Sci 2000;21:177-181.

$\checkmark 14$ To WC, Traquina DN: Neuralgic amyotrophy presenting with bilateral vocal cord paralysis in a child: a case report. Int J Pediatr Otorhinolaryngol 1999;48:251-254. 